\title{
Dynamics of Propane in Silica Mesopores Formed upon Propylene Hydrogenation over Pt Nanoparticles by Time-Resolved FT-IR Spectroscopy
}

\author{
Walter Wasylenko and Heinz Frei* \\ Physical Biosciences Division, Lawrence Berkeley National Laboratory, University of \\ California, Berkeley, CA 94720
}




\begin{abstract}
Propylene hydrogenation over Pt nanoparticles supported on mesoporous silica type SBA-15 was monitored by time-resolved FT-IR spectroscopy at 23 ms resolution using short propylene gas pulses that joined a continuous flow of hydrogen in $\mathrm{N}_{2}(1 \mathrm{~atm}$ total pressure). Experiments were conducted in the temperature range $323-413 \mathrm{~K}$. Propane was formed within 100 milliseconds or faster. The $\mathrm{CH}$ stretching region revealed distinct bands for propane molecules emerging inside the nanoscale channels of the silica support. Spectral analysis gave the distribution of the propane product between support and surrounding gas phase as function of time. Kinetic analysis showed that the escape of propane molecules from the channels occurred within hundreds of milliseconds $(3.1 \pm 0.4$

$\mathrm{s}^{-1}$ at $383 \mathrm{~K}$ ). A steady state distribution of propane between gas phase and mesoporous support is established as the product is swept from the catalyst zone by the continuous flow of hydrogen co-reactant. This is the first direct spectroscopic observation of emerging products of heterogeneous catalysis on nanoporous supports under reaction conditions.
\end{abstract}




\section{Introduction}

Mesoporous silica materials are attractive supports for metal nanoparticle catalysts because of the very high surface area, adjustable pore size, and potential for alignment of the particles. For example, the silica material of type SBA-15 has a 1dimensional channel system with pore diameter in the range 5-30 $\mathrm{nm} .{ }^{1}$ Occlusion of metal nanoparticles in the size range $1-10 \mathrm{~nm}$ is expected to leave sufficient space in the channels for easy uptake or release of reactants and products. Somorjai and coworkers have recently introduced synthetic methods for SBA-15 supported monodisperse Pt nanoparticle catalysts of varying metal particle size. ${ }^{2,3}$ Catalytic activities were tested for ethylene hydrogenation and ethane hydrogenolysis, and rates were found to be comparable to the most efficient Pt catalysts on conventional supports. The precise control of the structural aspects of monodisperse metal nanoparticles on mesoporous supports offers opportunities for evaluating systematically the influence of catalyst properties on catalytic performance. An important question posed by the use of these new catalyst supports is the influence of the nanoscale channels on the behavior of intermediates and final products under reaction conditions. In particular, it is important to gain knowledge about the residence time of emerging reaction products inside the nanopores and the kinetics of escape from the support into the surrounding gas phase. No direct observations of such processes have been reported to date.

We have recently employed time-resolved rapid-scan FT-IR spectroscopy to monitor the surface ethyl to ethane interconversion over Pt nanoparticles supported on a 
conventional alumina catalyst support under reaction conditions $(323-473 \mathrm{~K}, 1 \mathrm{~atm}){ }^{4,5}$ The decay of the $\mathrm{C}_{2} \mathrm{H}_{5} \mathrm{Pt}$ species was found to exhibit the same temporal behavior as the rise of ethane, demonstrating directly the kinetic significance of the intermediate. The work showed that the time-resolved FT-IR method is capable of detecting and monitoring transient surface intermediates on the $20 \mathrm{~ms}$ time scale under reaction conditions, including in spectral regions with strong overlap with reactant absorption bands. Therefore, the method might be suitable for the detection and kinetic analysis of intermediates and emerging products inside the channels of metal nanoparticles supported on SBA-15. To address the questions outlined above, we have selected for a case study the hydrogenation of propylene over SBA-15 supported Pt nanoparticles.

The most detailed insight into the mechanism of propylene hydrogenation on a $\mathrm{Pt}$ surface under close to ambient conditions was obtained in a spectroscopic study of the $\mathrm{CH}$ stretch region using infrared-visible sum frequency generation (SFG). ${ }^{6}$ In the presence of 720 Torr of hydrogen and 40 Torr of propylene at $295 \mathrm{~K}$ over a Pt single crystal surface, propylene hydrogenation was found to proceed in two steps: Hydrogenation of physisorbed, $\pi$-bonded propylene to 2-propyl surface intermediate $\left(\mathrm{C}_{3} \mathrm{H}_{7} \mathrm{Pt}\right)$ followed by hydrogenation of $\mathrm{C}_{3} \mathrm{H}_{7} \mathrm{Pt}$ to propane, with the latter as the ratelimiting step. Furthermore, surface species formed upon adsorption of propylene, propane, or propyl iodide molecules on single crystal Pt surfaces under ultra high vacuum conditions or on supported Pt particles have been observed by infrared, SFG or electron loss spectroscopy. This includes propylidyne $\left(\mathrm{C}_{2} \mathrm{H}_{5} \mathrm{CPt}_{3}\right)^{6-9}, 1$-propyl $\left(\mathrm{CH}_{3} \mathrm{CH}_{2} \mathrm{CH}_{2} \mathrm{Pt}\right)$ and 2-propyl $\left(\mathrm{CH}_{3} \mathrm{CHPtCH}_{3}\right) .{ }^{6,10,11}$ 
In this paper, we report a rapid-scan FT-IR study of propylene hydrogenation over $\operatorname{Pt}(1.7 \mathrm{~nm}) / \mathrm{SBA}-15$ catalyst at 1 atm in the temperature range $323-413 \mathrm{~K}$. Propane evolution inside the mesoporous support and escape into the surrounding gas phase was directly observed.

\section{Experimental}

Time-resolved FT-IR spectra were recorded in the rapid-scan mode on a Bruker model IFS88 spectrometer equipped with a $\mathrm{HgCdTe}$ PV detector Kolmar Technologies model KMPV8-1-J2 (8 $\mu$ m bandgap), a HgCdTe PV detector Kolmar Technologies model KMPV11-1-J2 (12 $\mu \mathrm{m}$ bandgap), or a InSb detector Kolmar Technologies model KISDP-1-J2, or on a Bruker model IFS66 spectrometer equipped with a HgCdTe PV detector Kolmar Technologies model KMPV8-1-J2 (8 $\mu \mathrm{m}$ bandgap) as described previously. The method is described briefly below. The mirror velocity was $160 \mathrm{kHz}$, and the spectral resolution was either $4 \mathrm{~cm}^{-1}$ or $2 \mathrm{~cm}^{-1}$. For obtaining the $2 \mathrm{~cm}^{-1}$ resolution spectra an infrared filter that blocks all the IR light except between $3930-2273 \mathrm{~cm}^{-1}$ (OCLI model No. W03506-6) was used. The protocol for obtaining the transient spectra is described below where numbers in parenthesis refer to $2 \mathrm{~cm}^{-1}$ resolution experiments and the numbers outside parenthesis refer to experiments at $4 \mathrm{~cm}^{-1}$ resolution. Transient spectra are obtained by the recording of 99 interferograms (double-sided/forwardbackward) following a propylene pulse, corresponding to 396 single-sided interferograms. 
Single beam spectra obtained from the interferograms consisted of four $50 \mathrm{~ms}$ (or $90 \mathrm{~ms}$ ) time slices followed by three $100 \mathrm{~ms}$ (or $200 \mathrm{~ms}$ ) time slices, then a $10900 \mathrm{~ms}$ (or 18400 $\mathrm{ms}$ ) time slice, and the last time slice was $900 \mathrm{~ms}$ (or $1800 \mathrm{~ms}$ ). A total of 50 such sets of single beam spectra generated by 50 propylene pulses were stored as the result of one experiment. Final time-resolved spectra for a given time delay were obtained by calculating the ratio of each of the 50 corresponding stored single beam spectra against the single beam spectrum taken just before the pulse. The 50 ratioed spectra were then averaged to yield the absorbance time slice for a given time delay. The results of 10 such experiments were averaged for further $\mathrm{S} / \mathrm{N}$ improvement.

Slow runs on the time scale of seconds were conducted by a modified procedure. The method consisted of the recording of 396 interferograms following a propylene pulse (double-sided/forward-backward at $160 \mathrm{KHz}$ and $4 \mathrm{~cm}^{-1}$ or $2 \mathrm{~cm}^{-1}$ resolution). The 396 interferograms were divided into 10 buffers at varying time resolution. The first two buffers consisted of 8 interferograms followed by three buffers of 20 interferograms, one buffer of 40 interferograms, one of 60 interferograms, one of 80 interferograms, one of 100 interferograms, and the last buffer consisted of 40 interferograms. Hence, the data stored after each propylene pulse consisted of 10 averaged interferograms taken at 216 , $648,1404,2484,3564,5184,7884,11664,16524,20304 \mathrm{~ms}$ after the reactant pulse (midpoints) for $2 \mathrm{~cm}^{-1}$ resolution experiments, and the data stored after each propylene pulse consisted of 10 averaged interferograms taken at 128, 384, 832, 1472, 2112, 3072, $4672,6912,9792,12032 \mathrm{~ms}$ after the reactant pulse (midpoints) for $4 \mathrm{~cm}^{-1}$ resolution experiments. 
SBA-15-supported Pt catalyst (3\% Pt, 1.7 nm Pt nanoparticles, pore diameter 11.2

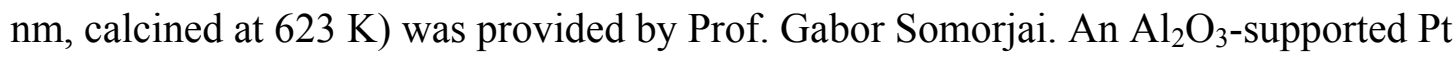
catalyst (Exxon HFR-100, 5\% Pt, calcined at $823 \mathrm{~K}$, BET surface area $96 \mathrm{~m}^{2} \mathrm{~g}^{-1}$ ) provided by Dr. Joel Ager (LBNL) was also used in some experiments for the comparison purposes. The catalysts were prepared in the form of a pressed wafer with an embedded W grid. The latter is made of a 0.49 in. diameter tungsten foil (thickness 0.002 in.) featuring laser-drilled 0.012 in. holes. The grid, which was held by a Ni jaw similar to a design described by Yates $^{12}$ was electrically heated and the temperature monitored by a thermocouple mounted on the $\mathrm{W}$ grid. The catalyst was situated in the center of home built $100 \mathrm{~cm}^{3}$ stainless steel reactor cell equipped with two flange-mounted $\mathrm{BaF}_{2}$ windows for transmission infrared spectroscopy. The $\mathrm{Al}_{2} \mathrm{O}_{3}$ catalyst was transparent in the region $5000-800 \mathrm{~cm}^{-1}$ (reduced sensitivity below $1100 \mathrm{~cm}^{-1}$ because of Al-O stretch absorption), while the SBA-15 catalyst was transparent in the region $5000-1300 \mathrm{~cm}^{-1}$. The continuous flow of a $\mathrm{H}_{2} / \mathrm{N}_{2}$ mixture (ratio 0.067 ) with a flow rate of $4.5 \mathrm{~L} / \mathrm{min}$ at a total pressure $1 \mathrm{~atm}$ entered the cell through a $1 / 4$ in. tube on one side and exited through an exhaust line on the other. The flow of each gas was regulated by MFC valves (MKS Instruments). More details of the reactor setup are described in previous reports. ${ }^{4,5}$ Millisecond time resolution was achieved by the synchronization of propylene pulses of $30 \mathrm{~ms}$ duration with the forward motion of the interferometer mirror. The spacing between propylene pulses was $12.8 \mathrm{~s}$ (resolution $4 \mathrm{~cm}^{-1}$ ) or $21.6 \mathrm{~s}$ (resolution $2 \mathrm{~cm}^{-1}$ ), which assured that all reaction had ceased prior to arrival of a fresh pulse. The pulses were released through a fast value (General Valve Series 99 pulsed valve coupled with an 
Iota One pulse driver) and contained $15 \mu \mathrm{mol}$ propylene. The pulses merged with the continuous $\mathrm{H}_{2} / \mathrm{N}_{2}$ flow $7 \mathrm{~cm}$ upstream from the center of the reactor cell. Before each series of experiments, the catalyst was exposed for two hours to a $\mathrm{H}_{2} / \mathrm{N}_{2}$ flow at $473 \mathrm{~K}$. Propylene (Matheson Tri-Gas, 99.5\%), hydrogen (Air Gas, 99.9999\%), and nitrogen (Air Gas, 99.9995\%) gas were used as received.

\section{Results and Discussion}

Figure 1 shows survey absorbance spectra of four selected transient time slices at $4 \mathrm{~cm}^{-1}$ resolution recorded for catalytic propylene hydrogenation at $323 \mathrm{~K}$. In these experiments, a mixture of $6.7 \% \mathrm{H}_{2}$ in $\mathrm{N}_{2}$ at flow rate of $4.5 \mathrm{~L} \mathrm{~min}^{-1}$ was used (total pressure $1 \mathrm{~atm}$ ), and the catalysis initiated with a $15 \mu \mathrm{mol}$ propylene pulse. The bottom trace is the initial spectrum recorded after release of the propylene pulse, with its midpoint delayed by $35 \mathrm{~ms}$ relative to the opening of the pulsed gas valve. As expected, propylene gas phase bands $\left(3150-2850 \mathrm{~cm}^{-1}, v(\mathrm{CH}) ; 1830 \mathrm{~cm}^{-1}, 2 v_{13} ; 1647 \mathrm{~cm}^{-1}\right.$, $\left.v(\mathrm{C}=\mathrm{C}) ; 1472,1448 \mathrm{~cm}^{-1}, \delta\left(\mathrm{CH}_{3}\right)\right)^{13}$ dominate the first spectrum and then decrease principally because of removal of the reactant from the infrared viewing zone by gas flow. The loss of reactants is most readily seen by the decreasing intensity of the propylene bands below $2000 \mathrm{~cm}^{-1}$. The kinetics of this process was presented in detail in our previous time-resolved FT-IR studies of ethylene hydrogenation. ${ }^{4,5}$ On the other hand, the absorption profile of $\mathrm{CH}$ stretch modes in the $3000-2800 \mathrm{~cm}^{-1}$ region seems not to decrease but changes markedly its shape, indicating that the propylene bands are replaced 
by new ones that might originate from transient intermediates and/or propane growth.

Detection of surface intermediates and final product required accurate spectral subtraction of the propylene bands. For this purpose, gas phase $\mathrm{C}_{3} \mathrm{H}_{6}$ bands were subtracted using a multiplication factor that resulted in complete removal of the intense $\mathrm{C}=\mathrm{C}$ stretch absorption at $1650 \mathrm{~cm}^{-1}$ and the overtone at $1850 \mathrm{~cm}^{-1}$, regions free of spectral overlap with any other species (for $2 \mathrm{~cm}^{-1}$ resolution experiments in which undersampling limited the spectral region to $4000-2000 \mathrm{~cm}^{-1}$, cancellation of the $\mathrm{CH}$ stretch absorption of propylene at $>3000 \mathrm{~cm}^{-1}$ was used for determination of the multiplication factor). All subsequent spectra shown in this paper have the gas phase propylene bands removed by this procedure. Observations in the infrared $\mathrm{CH}$ stretching region and the fingerprint region revealed distinct chemical processes of propylene to propane conversion. In the following, spectra of the two regions will be presented and discussed in turn.

\subsection{Transient spectra of the $\mathrm{CH}$ stretching region}

Time-resolved measurements of propylene hydrogenation were conducted at 323, 383, and $413 \mathrm{~K}$. Figure 2 shows for each reaction temperature a spectrum at early and at late times: The initial time slice was recorded at $56 \mathrm{~ms}$ (panel A), and a $972 \mathrm{~ms}$ spectrum is

shown panel B. The spectral resolution is $2 \mathrm{~cm}^{-1}$. While the early and late spectra of the run at $413 \mathrm{~K}$ look very similar, this is not the case for experiments at the lower temperatures. The $972 \mathrm{~ms}$ band profile of the $383 \mathrm{~K}$ experiment shows growth of small but sharp peaks at 2968 and $2885 \mathrm{~cm}^{-1}$ that are barely visible in the $56 \mathrm{~ms}$ trace. At $323 \mathrm{~K}$, these sharp features are very weak but still discernable in the $972 \mathrm{~ms}$ spectrum, but 
completely absent in the $56 \mathrm{~ms}$ profile. This shows that more than one species absorbs in this spectral region, and that a process is temporally resolved at the lower temperatures that is too fast for detection at $413 \mathrm{~K}$. Since the sharp peaks at 2968 and $2885 \mathrm{~cm}^{-1}$ coincide with the $\mathrm{Q}$ branches of the gas phase propane absorptions $v_{15}(\mathrm{CH})$ and $v_{16}(\mathrm{CH}),{ }^{14}$ the observed process is attributed to the escape of propane product molecules from the mesopores of the silica support into to surrounding gas phase. This interpretation was confirmed by conducting the same propylene hydrogenation experiment with amorphous $\mathrm{Al}_{2} \mathrm{O}_{3}$-supported Pt catalyst, which does not possess mesoscale channels. In this case, the $3100-2800 \mathrm{~cm}^{-1}$ absorption (after propylene subtraction) is identical to the gas phase propane spectrum for every time slice at all temperatures examined. Therefore, we conducted a spectral analysis of the experiments with Pt/SBA-15 based on the assumption that the observed absorption profile in the $3100-2800 \mathrm{~cm}^{-1}$ region is composed of two components, namely gas phase propane and propane molecules adsorbed inside the silica mesopores.

Faithful recording of infrared ro-vibrational bands of gas phase propane requires a spectral resolution well below $1 \mathrm{~cm}^{-1}$. However, the data acquisition electronics of our FT-IR instrument limits the file-size of the very large time-resolved interferogram stacks such that the spectral resolution cannot exceed $2 \mathrm{~cm}^{-1}$. Nevertheless, as our analysis shows, use of gas phase reference spectra of propane and propylene recorded with identical parameters as used in the time-resolved measurements adequately compensates for the systematic errors. Taking the disappearance of the sharp $v_{15}$ and $v_{16} \mathrm{Q}$ branch peaks at 2968 and $2885 \mathrm{~cm}^{-1}$ as criterion for quantitative subtraction of the gas phase 
propane component, the spectrum of the pore component of each time slice was computed and the results shown in Figure 3. Each panel of the Figure shows three colorcoded spectral traces for time points $56 \mathrm{~ms}$ and $756 \mathrm{~ms}$ of catalysis runs at 323,383 , and $413 \mathrm{~K}$. The observed spectrum (after propylene subtraction) is traced in black, the gaseous propane component in green, and the pore component in red. For comparison, a spectrum of static spectrum of gas phase propane recorded with the same instrument parameters as used in the time-resolved experiments is shown in Figure 4a.

Initial inspection of the spectral decomposition confirms trends consistent with escape of propane molecules from the pores into the gas phase. For example, at the lowest temperature $(323 \mathrm{~K})$, the earliest time slice shows no gas phase propane, but the contribution of gaseous component to the initial spectrum increases with rising temperature. Furthermore, growth of the gas phase propane component over the initial $700 \mathrm{~ms}$ period is observed for experiments at 323 and $383 \mathrm{~K}$, but seems to have reached its maximum intensity already at $56 \mathrm{~ms}$ for catalysis at the highest temperature, $413 \mathrm{~K}$. We conclude that at temperatures in the range $300-400 \mathrm{~K}$, desorption of propane product molecules from the mesoporous support proceeds on the hundreds of millisecond time scale. The infrared spectrum of propane inside room temperature silica mesopores in equilibrium with the gas phase propane, shown in Figure 4b, was found to be identical with the time resolved pore spectra at $323 \mathrm{~K}$ (Figure 3, red traces). Both spectra show peaks at $2963,2941,2905$, and $2876 \mathrm{~cm}^{-1}$, and the same relative intensities. We conclude that the spectrum obtained by subtraction of the gas phase propane bands from the observed transient infrared spectra originates from propane product residing inside the 
silica mesopores. While the propane pore spectra look identical for all traces at 323 and $383 \mathrm{~K}$, small but clearly visible differences in the relative intensities of the four peaks are noted in the $413 \mathrm{~K}$ experiment. These may reflect changes in the population of propane adsorption sites in the silica mesopores with increasing temperature.

Kinetic analysis of the time-resolved runs revealed quantitative aspects of the propane evolution inside the mesopores and subsequent escape into the gas phase. We present here the data for experiments conducted at $383 \mathrm{~K}$, the temperature at which the kinetics of the main processes could be determined most accurately. Spectral time slices observed at 216, 648, 1404, and $2484 \mathrm{~ms}$ are shown in Figure 5A, and the kinetic behavior of the integrated intensity of the entire propane absorption between 3100 and $2800 \mathrm{~cm}^{-1}$ is given in Figure 5B. The temporal behavior of the overall propane intensity is best interpreted by considering the corresponding data for the two components; the gaseous propane component, shown in Figure 6, and the pore component, Figure 7. Starting with the kinetic behavior of the gaseous $\mathrm{C}_{3} \mathrm{H}_{8}$ product, Figure $6 \mathrm{~B}$, the rise on the hundreds of ms time scale and decay within about $5 \mathrm{~s}$ are attributed to escape of the propane molecules from the silica mesopores and removal by rapid gas flow, respectively. These processes can be described by a model of two consecutive steps A $\rightarrow$ B $\rightarrow \mathrm{C}$ where $\mathrm{A}$ is propane residing inside the silica mesopores, $\mathrm{B}$ is gaseous propane in the infrared viewing zone, and $\mathrm{C}$ is propane removed from the viewing zone by the rapid gas flow. If $\mathrm{k}_{1}$ is the rate constant for $\mathrm{A} \rightarrow \mathrm{B}$ and $\mathrm{k}_{2}$ the rate constant for the $\mathrm{B} \rightarrow \mathrm{C}$ step, the time-dependence of the infrared absorbance of gaseous propane B at time $t$ is ${ }^{15}$

$$
\mathrm{A}^{\mathrm{B}}=\mathrm{A}_{0}\left(\mathrm{k}_{1} /\left(\mathrm{k}_{2}-\mathrm{k}_{1}\right)\right)\left[\exp \left(-\mathrm{k}_{1} \mathrm{t}\right)-\exp \left(-\mathrm{k}_{2} \mathrm{t}\right)\right]
$$


$\mathrm{A}^{\mathrm{B}}$ was taken as the peak absorbance of gaseous propane at $2968 \mathrm{~cm}^{-1}$. A rate constant $\mathrm{k}_{1}$ $=3.1 \pm 0.4 \mathrm{~s}^{-1}$ was derived from the least squares fit of eq. 1 , indicating a $1 / \mathrm{e}$ escape time of $322 \mathrm{~ms}$ for propane from the SBA-15 channels (in the presence of $1 \mathrm{~atm}$ of $\mathrm{H}_{2}-\mathrm{N}_{2}$ gas). The residence time of the gaseous product of $1.6 \mathrm{~s}\left(\mathrm{k}_{2}=0.61 \pm 0.07 \mathrm{~s}^{-1}\right)$ is limited by removal through continuous $\mathrm{H}_{2}-\mathrm{N}_{2}$ flow. Interestingly, the same decay rate of $0.61 \pm 0.03$ $\mathrm{s}^{-1}$ was obtained for the infrared band at $2963 \mathrm{~cm}^{-1}$ (peak intensity) attributed to propane molecules inside the silica pores, Figure 7B. This finding indicates that exchange of propane molecules between pores and surrounding gas phase is fast on the time scale of removal of the alkane product from the catalyst zone. This implies that the kinetics of the pore component is influenced not just by one, but by two processes: desorption from the mesopores into the gas phase, and decrease of the overall propane concentration due to gas flow. A direct measure of the escape rate of propane from the pores is obtained by plotting the fraction of propane molecules in the pores as function of time. Figure 8 shows the ratio of the integrated absorbance of $\mathrm{C}_{3} \mathrm{H}_{8}$ in the pores (bands of Figure $7 \mathrm{~A}$ ) and the integrated absorbance of the overall propane spectrum (Figure 5A). We find that the steady state distribution between propane inside and outside the pores is reached within $2 \mathrm{~s}$. The rate constant of $1.9 \pm 0.2 \mathrm{~s}^{-1}$ at which the asymptotic distribution between the two phases is reached is close to the rise of the gaseous propane spectrum, $3.1 \pm 0.4 \mathrm{~s}$ ${ }^{1}$ (Figure 6B). In light of the systematic errors associated with the intensity measurements discussed above, in particular the lack of spectral resolution for accurate recording of the gas phase bands, we believe that the data directly confirm the process of escape of the propane product from the $11 \mathrm{~nm}$ pores of the silica support into the gas phase. Direct 
observation of the dynamics of a catalysis product inside a mesoporous support and desorption from the support has not been reported before.

The kinetic behavior of propane inside pores (Figure 7B) as well as the temporal behavior of the overall propane intensity (Figure $5 \mathrm{~B}$ ) show a very short rise that is complete within $100 \mathrm{~ms}$. The rise is most probably due to hydrogenation of the presumed precursor, surface propyl $\left(\mathrm{C}_{3} \mathrm{H}_{7} \mathrm{Pt}\right)$. Using again a sequential 2-stage process $\mathrm{A} \rightarrow \mathrm{B} \rightarrow \mathrm{C}$ to describe the kinetics (here, $\mathrm{A}$ is surface propyl, $\mathrm{B}$ is propane inside pores, $\mathrm{C}$ is gas phase propane), a fit of the data points shown in Figure 7B gives a rate constant $\mathrm{k}_{1}(\mathrm{~A} \rightarrow$ B) $=18 \pm 1 \mathrm{~s}^{-1}$. This corresponds to a rise time of $56 \mathrm{~ms}$ for surface propyl to propane hydrogenation at $383 \mathrm{~K}$. The hydrogenation step is expected to be substantially slower at $323 \mathrm{~K}$. We determined that the rate of growth of the propane inside the pores, which is the dominant component at $323 \mathrm{~K}$ (Figure 3 ) as $\mathrm{k}_{1}=11.1 \pm 0.9 \mathrm{~s}^{-1}$. This corresponds to a rise time of $90 \mathrm{~ms}$.

\subsection{Transient spectra of the fingerprint region}

In light of the $90 \mathrm{~ms}$ rise time estimated for pore propane at $323 \mathrm{~K}$, it should be possible to detect its presumed precursor, a surface propyl species at early times, perhaps up to about $200 \mathrm{~ms}$. Because of the high intensity of propylene and propane $\mathrm{CH}$ stretch absorptions, it might be difficult to detect a short lived propyl intermediate in the 3000 $\mathrm{cm}^{-1}$ region. However, according to literature reports of static infrared spectra of Pt surface propyl species, absorptions in the $1400 \mathrm{~cm}^{-1}$ region are among the strongest. ${ }^{10}$ Hence, time-resolved spectra in the region below $1500 \mathrm{~cm}^{-1}$ are most likely to reveal 
bands of the surface reaction intermediate. Overlap of closely spaced $\mathrm{CH}$ bending absorptions of gas phase propylene between 1500 and $1400 \mathrm{~cm}^{-1}$ still posed a challenge, but a sharp, reproducible band was detected at $1456 \mathrm{~cm}^{-1}$ that dominates spectral time slices in the initial $200 \mathrm{~ms}$. Spectra taken at 122, 366, and $793 \mathrm{~ms}$ are displayed in Figure 9. The peak decays within a few hundred ms and is replaced by a rapidly growing band at $1469 \mathrm{~cm}^{-1}$. The latter is very close to the $v_{24} \mathrm{CH}_{3}$ bending mode of gas phase propane. ${ }^{14}$ Corresponding time-resolved traces of the $\mathrm{CH}$ stretching region show that at times shorter than $1 \mathrm{~s}$ most of the propane in experiments at $323 \mathrm{~K}$ still remains adsorbed on SBA-15. Hence, we assign the $1469 \mathrm{~cm}^{-1}$ band to $\mathrm{C}_{3} \mathrm{H}_{8}$ product residing in the pores. The only infrared feature that we have not been able to assign is a broad absorption at $1373 \mathrm{~cm}^{-1}$. The band was also observed in catalytic runs using conventional $\mathrm{Pt} / \mathrm{Al}_{2} \mathrm{O}_{3}$ catalyst. It shows only minor intensity changes, suggesting that it might originate from the $1375 \mathrm{~cm}^{-1}$ absorption of propylidyne $\left(\mathrm{CH}_{3} \mathrm{CH}_{2} \mathrm{CPt}_{3}\right)$, a spectator species known to be formed upon propylene adsorption on $\mathrm{Pt} .{ }^{6}$ However, this possibility is ruled out by the fact that propylidyne has a more intense infrared $\mathrm{CH}$ bending mode at $1450 \mathrm{~cm}^{-1}, 8,11$ which is not observed.

\section{Conclusions}

Time-resolved FT-IR monitoring of propylene hydrogenation over Pt nanoparticles supported on mesoporous silica allowed us to detect the formation of propane molecules inside the nanoscale channels and follow the kinetics of escape into the surrounding gas phase. At reaction temperatures in the range 323 to $413 \mathrm{~K}$, propane 
molecules are formed inside the mesopores by hydrogenation of surface propyl species in $100 \mathrm{~ms}$ or less. By virtue of distinct infrared bands for propane inside the pores, spectral analysis allowed the study of the kinetics of product desorption from the silica channels into the gas phase. The process occurs on the hundreds of millisecond time scale. A steady state distribution of propane between gas and mesopore phase is maintained as the product is removed from the catalyst zone over a time span of a several seconds by the continuous gas flow of $\mathrm{H}_{2}$ co-reactant (diluted in $\mathrm{N}_{2}$ ). This study is the first to report direct spectroscopic observation of emerging products of heterogeneous catalysis on nanoporous supports under reaction conditions.

\section{Acknowledgment}

This work was supported by the Director, Office of Science, Office of Basic Energy Sciences, Division of Chemical, Geological and Biosciences of the U.S. Department of Energy under Contract No. DE-AC03-76SF00098. 


\section{References}

1. Zhao, D.; Feng, J. Huo, Q.; Melosh, N.; Fredrickson, G.H.; Chmelka, B.F.; Stucky, G.D. Science 1998, 279, 548.

2. Song, H.; Rioux, R.M.; Hoefelmeyer, J.D.; Komor, R.; Niesz, K.; Grass, M.; Yang, P.; Somorjai, G.A. J. Am. Chem. Soc. 2006, 128, 3027.

3. Rioux, R,M.; Song, H.; Hoefelmeyer, J.D.; Yang, P.; Somorjai, G.A. J. Phys. Chem. B 2005, 109, 2192.

4. Wasylenko, W.; Frei, H. J. Phys. Chem. B 2005, 109, 16873.

5. $\quad$ Ko, M.K.; Frei, H. J. Phys. Chem. B 2004, 108, 1805.

6. Cremer, P.S.; Su, X.; Shen, Y.R.; Somorjai, G.A. J. Phys. Chem. 1996, 100, 16302.

7. Koestner, R.J.; Frost, J.C.; Stair, P.C.; Van Hove, M.A.; Somorjai, G.A. Surf. Sci. 1982, 116,85 .

8. Zaera, F.; Chrysostomou, D. Surf. Sci. 2000, 457, 71.

9. Chesters, M.A.; De La Cruz, C.; Gardner, P.; McCash, E.M.; Pudney, P.; Shahid, G.; Sheppard, N. J. Chem. Soc. Faraday Trans. 1990, 86, 2757.

10. Chrysostomou, D.; French, C.; Zaera, F. Catal. Lett. 2000, 69, 117.

11. Shahid, G.; Sheppard, N. Spectrochim. Acta 1990, 46A, 999.

12. Basu, P.; Ballinger, T.H.; Yates, J.T., Jr. Rev. Sci. Instrum. 1988, 59, 1321.

13. Herzberg, G. Infrared and Raman Spectra; Van Nostrand: New York, 1945; p. 355.

14. Herzberg, G. Infrared and Raman Spectra; Van Nostrand: New York, 1945; p. 361. 
15. Frost, A.A.; Pearson, R.G. Kinetics and Mechanism; Wiley: New York, 1961; p. 166. 


\section{Figure Captions}

Figure 1: $\quad$ Rapid-scan survey spectra of $\mathrm{C}_{3} \mathrm{H}_{6}+\mathrm{H}_{2}$ reaction induced by propylene pulses over Pt/SBA-15 at $323 \mathrm{~K}$ recorded at $25 \mathrm{~ms}$ resolution. Times refer to the time delay between the opening of the pulsed valve and the midpoint of the corresponding interferogram slice. Spectral resolution: 4 $\mathrm{cm}^{-1}$.

Figure 2: $\quad$ Rapid-scan spectra of $\mathrm{C}_{3} \mathrm{H}_{6}+\mathrm{H}_{2}$ catalysis at 323,383 , and $413 \mathrm{~K}$. The propylene bands were subtracted. A: Spectra observed $56 \mathrm{~ms}$ after initiation of catalysis. B: Spectra observed $972 \mathrm{~ms}$ after initiation of catalysis. Spectral resolution: $2 \mathrm{~cm}^{-1}$.

Figure 3: Temporal behavior of pore and gas phase components of $\mathrm{C}_{3} \mathrm{H}_{6}+\mathrm{H}_{2}$ catalysis at three different reaction temperatures: 323,383 , and $413 \mathrm{~K}$. For each temperature, time slices at $56 \mathrm{~ms}$ and $756 \mathrm{~ms}$ show observed spectrum (black, after subtraction of propylene band), gas component (green), and pore component (red). Spectral resolution: $2 \mathrm{~cm}^{-1}$.

Figure 4: $\quad$ Static FT-IR spectra of propane at room temperature. a: Gas phase propane ( 5 Torr, $2 \mathrm{~cm}^{-1}$ resolution). b: Propane in silica mesopores. The spectrum was determined by subtracting gas phase propane bands from the spectrum recorded when exposing 15 Torr propane to a pressed wafer of the mesoporous silica support $\left(0.25 \mathrm{~cm}^{-1}\right.$ resolution). Sharp features are due to incomplete subtraction of the Q-branches of gas phase propane. 
Figure 5: $\quad$ Rapid-scan spectra of $\mathrm{C}_{3} \mathrm{H}_{6}+\mathrm{H}_{2}$ catalysis of $383 \mathrm{~K}$. A: Spectral time slices are shown at 216,648, 1404 and $2484 \mathrm{~ms}$ after initiation of catalysis. The propylene bands were subtracted. Spectral resolution: $2 \mathrm{~cm}^{-1}$. B: Temporal behavior of the integrated absorbance. The solid line represents a fit according to eq. 1 .

Figure 6: Rapid-scan spectra of $\mathrm{C}_{3} \mathrm{H}_{6}+\mathrm{H}_{2}$ catalysis at $383 \mathrm{~K}$. A: Spectral time slices showing the gas phase propane component at 216, 648, 1404 and $2484 \mathrm{~ms}$ after initiation of catalysis. B: Kinetics of the peak absorbance of $2968 \mathrm{~cm}^{-}$ ${ }^{1}$. The solid line represents a fit according to eq. 1 .

Figure 7: Rapid-scan spectra of $\mathrm{C}_{3} \mathrm{H}_{6}+\mathrm{H}_{2}$ catalysis at $383 \mathrm{~K}$. A: Spectral time slices showing the pore component of propane at 216, 648, 1404, and $2484 \mathrm{~ms}$ after initiation of catalysis. B: Kinetics of peak absorbance of $2963 \mathrm{~cm}^{-1}$. The solid line represents a fit according to eq. 1 .

Figure 8: Temporal behavior of propane inside pores as fraction of total amount of propane upon $\mathrm{C}_{3} \mathrm{H}_{6}+\mathrm{H}_{2}$ catalysis at $383 \mathrm{~K}$. The ordinate represents the ratio of the integrated absorbance of propane inside pores (spectra of Figure 7) and the integrated absorbance of the observed propane band (spectra of Figure 5).

Figure 9: $\quad$ Rapid-scan spectra of $\mathrm{C}_{3} \mathrm{H}_{6}+\mathrm{H}_{2}$ catalysis at $323 \mathrm{~K}$. Spectral time slices showing the pore component of propane at 122,366, and $793 \mathrm{~ms}$ after initiation of catalysis. 


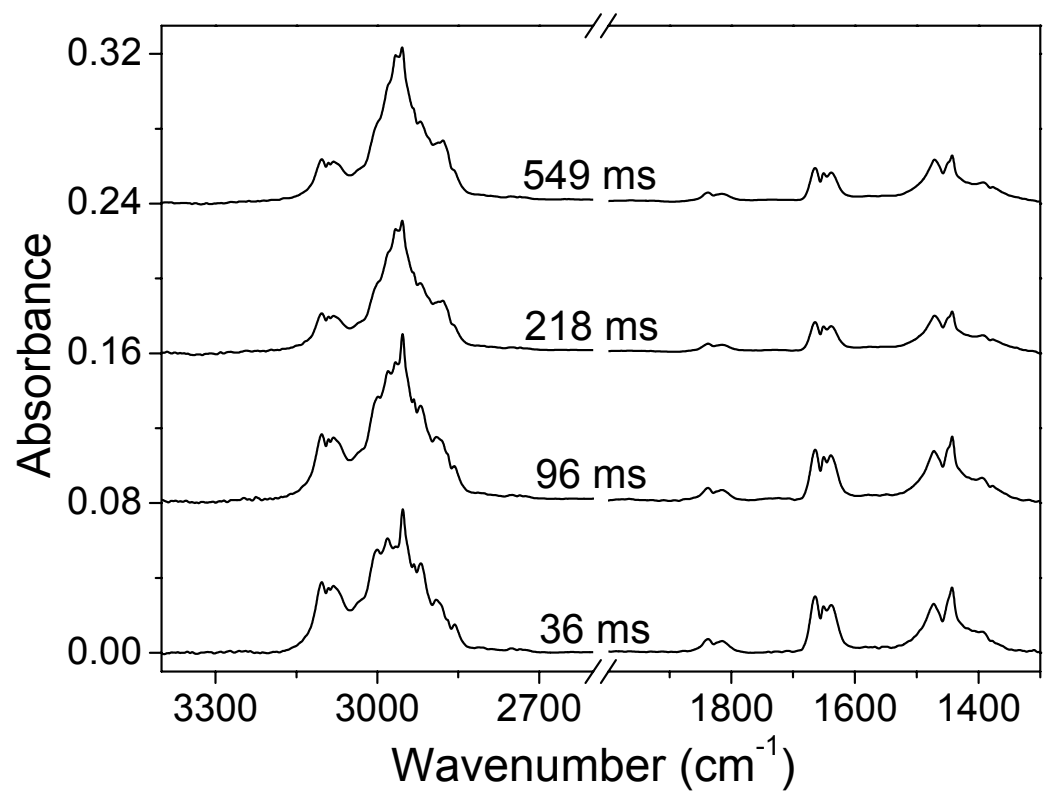

Figure 1. Rapid-scan survey spectra of $\mathrm{C}_{3} \mathrm{H}_{6}+\mathrm{H}_{2}$ reaction induced by propylene pulses over Pt/SBA-15 at $323 \mathrm{~K}$ recorded at $25 \mathrm{~ms}$ resolution. Times refer to the time delay between the opening of the pulsed valve and the midpoint of the corresponding interferogram slice. Spectral resolution: $4 \mathrm{~cm}^{-1}$. 

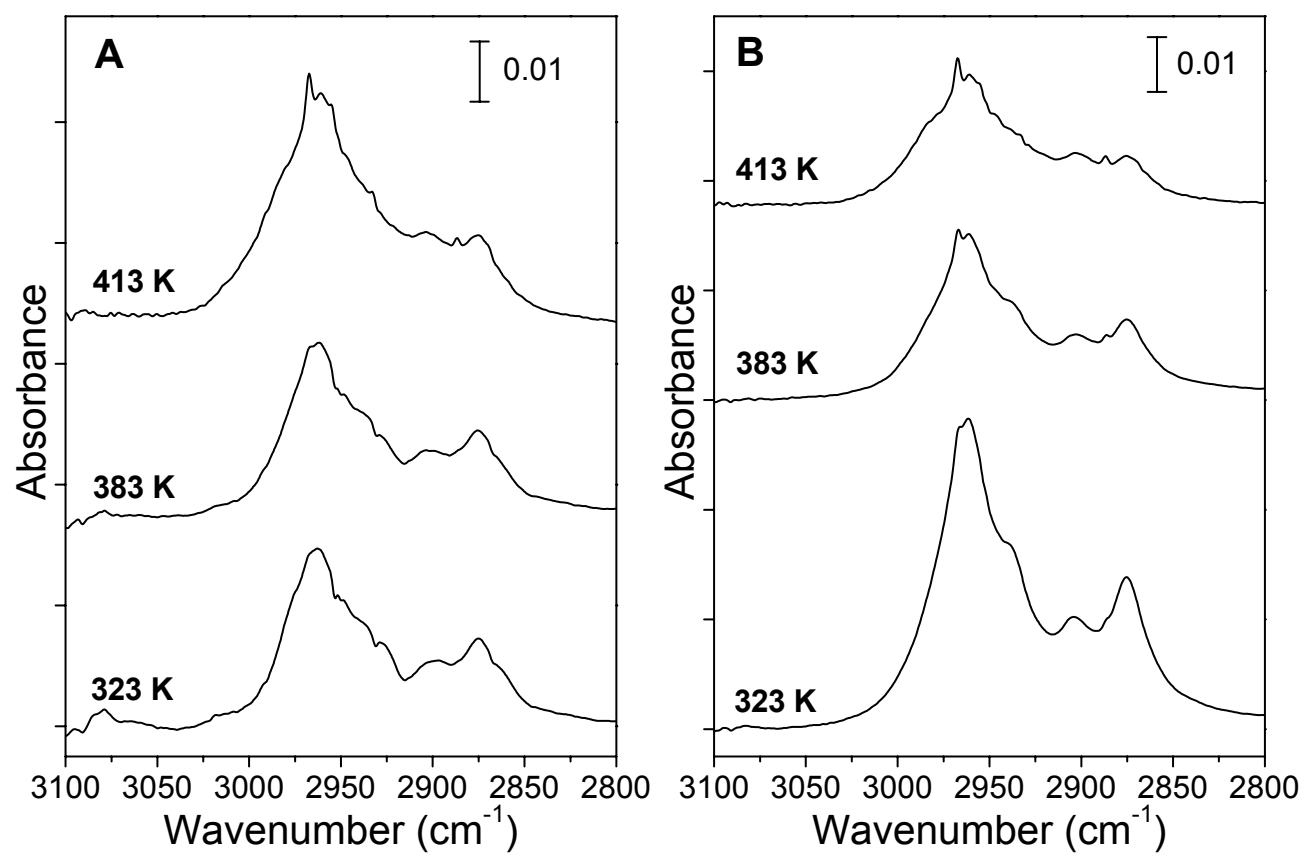

Figure 2. Rapid-scan spectra of $\mathrm{C}_{3} \mathrm{H}_{6}+\mathrm{H}_{2}$ catalysis at 323,383 , and $413 \mathrm{~K}$. The propylene bands were subtracted. A: Spectra observed $56 \mathrm{~ms}$ after initiation of catalysis. B: Spectra observed $972 \mathrm{~ms}$ after initiation of catalysis. Spectral resolution: $2 \mathrm{~cm}^{-1}$. 

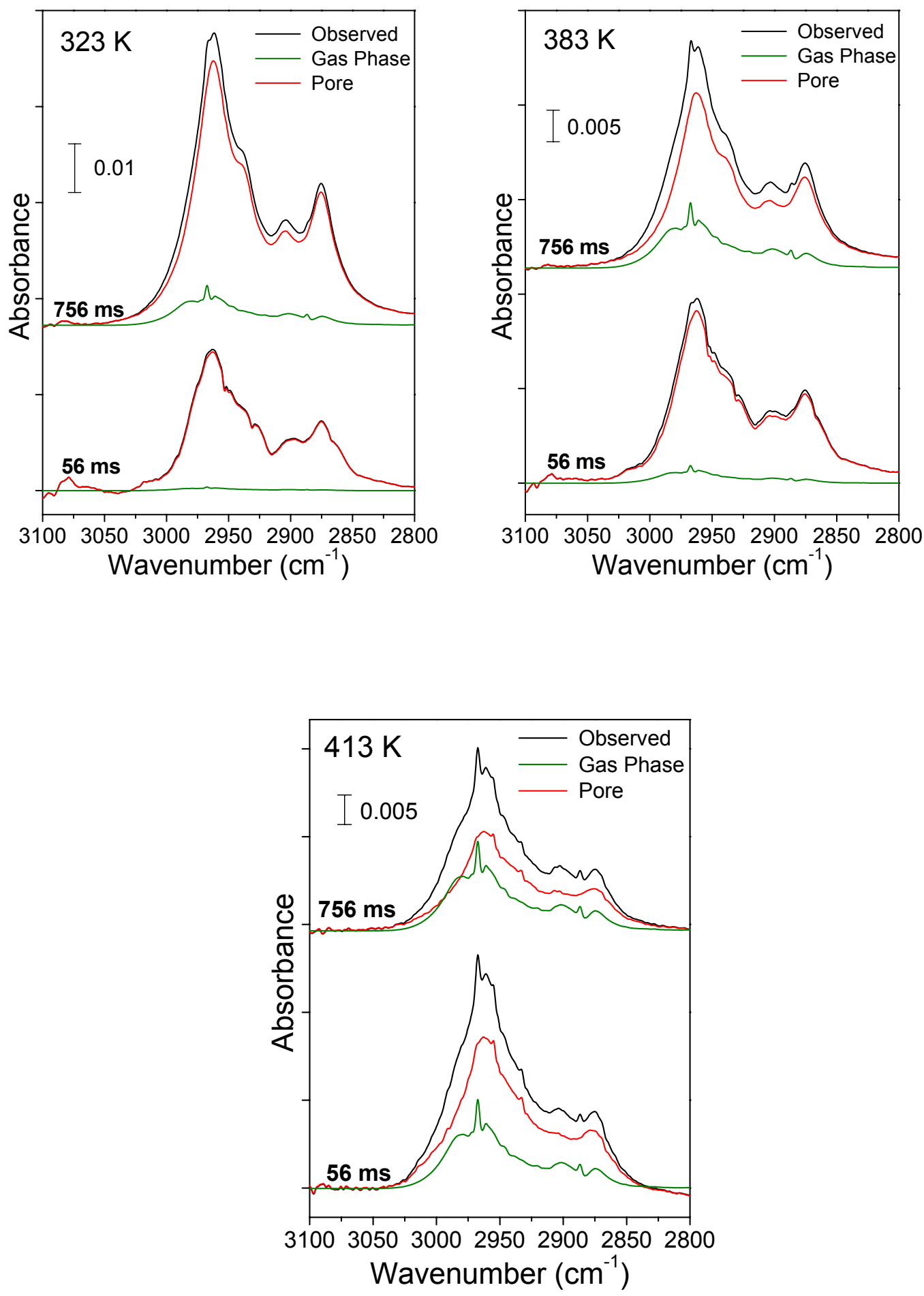

Figure 3. Temporal behavior of pore and gas phase components of $\mathrm{C}_{3} \mathrm{H}_{6}+\mathrm{H}_{2}$ catalysis at three different reaction temperatures: 323,383 , and $413 \mathrm{~K}$. For each temperature, time slices at $56 \mathrm{~ms}$ and $756 \mathrm{~ms}$ show observed spectrum (black, after subtraction of propylene band), gas component (green), and pore component (red). Spectral resolution: $2 \mathrm{~cm}^{-1}$. 


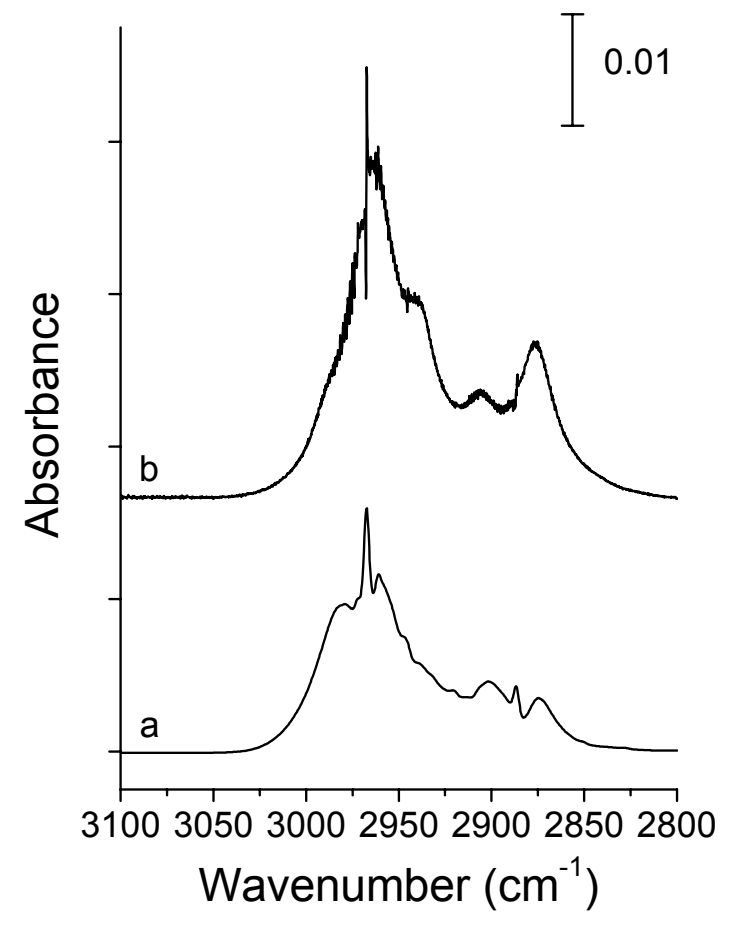

Figure 4. Static FT-IR spectra of propane at room temperature. a: Gas phase propane (5 Torr, $2 \mathrm{~cm}^{-1}$ resolution). b: Propane in silica mesopores. The spectrum was determined by subtracting gas phase propane bands from the spectrum recorded when exposing 15 Torr propane to a pressed wafer of the mesoporous silica support $\left(0.25 \mathrm{~cm}^{-1}\right.$ resolution). Sharp features are due to incomplete subtraction of the Q-branches of gas phase propane. 

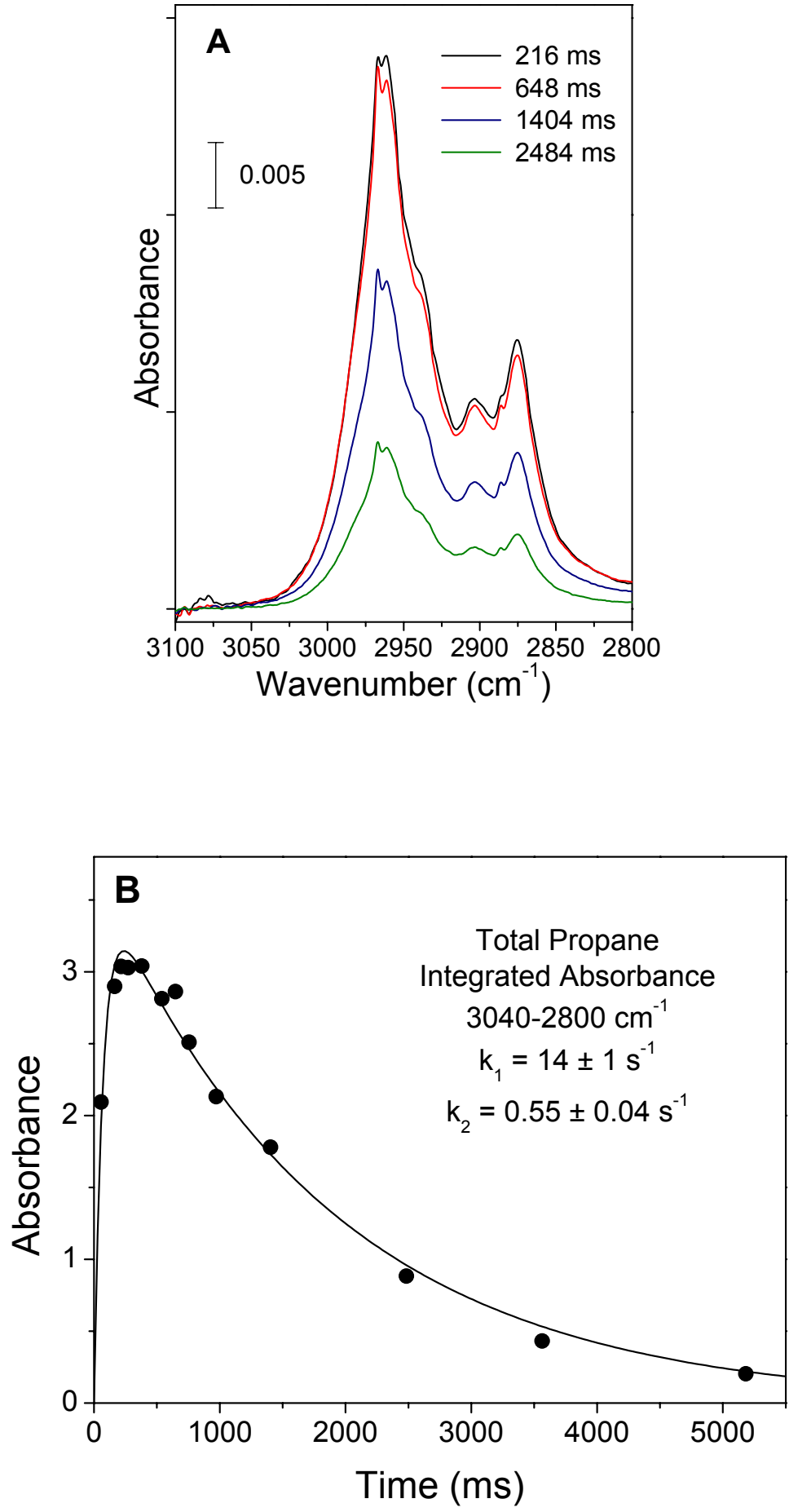

Figure 5. Rapid-scan spectra of $\mathrm{C}_{3} \mathrm{H}_{6}+\mathrm{H}_{2}$ catalysis of $383 \mathrm{~K}$. A: Spectral time slices are shown at 216, 648, 1404 and $2484 \mathrm{~ms}$ after initiation of catalysis. The propylene bands were subtracted. Spectral resolution: $2 \mathrm{~cm}^{-1}$. B: Temporal behavior of the integrated absorbance. The solid line represents a fit according to eq. 1 . 

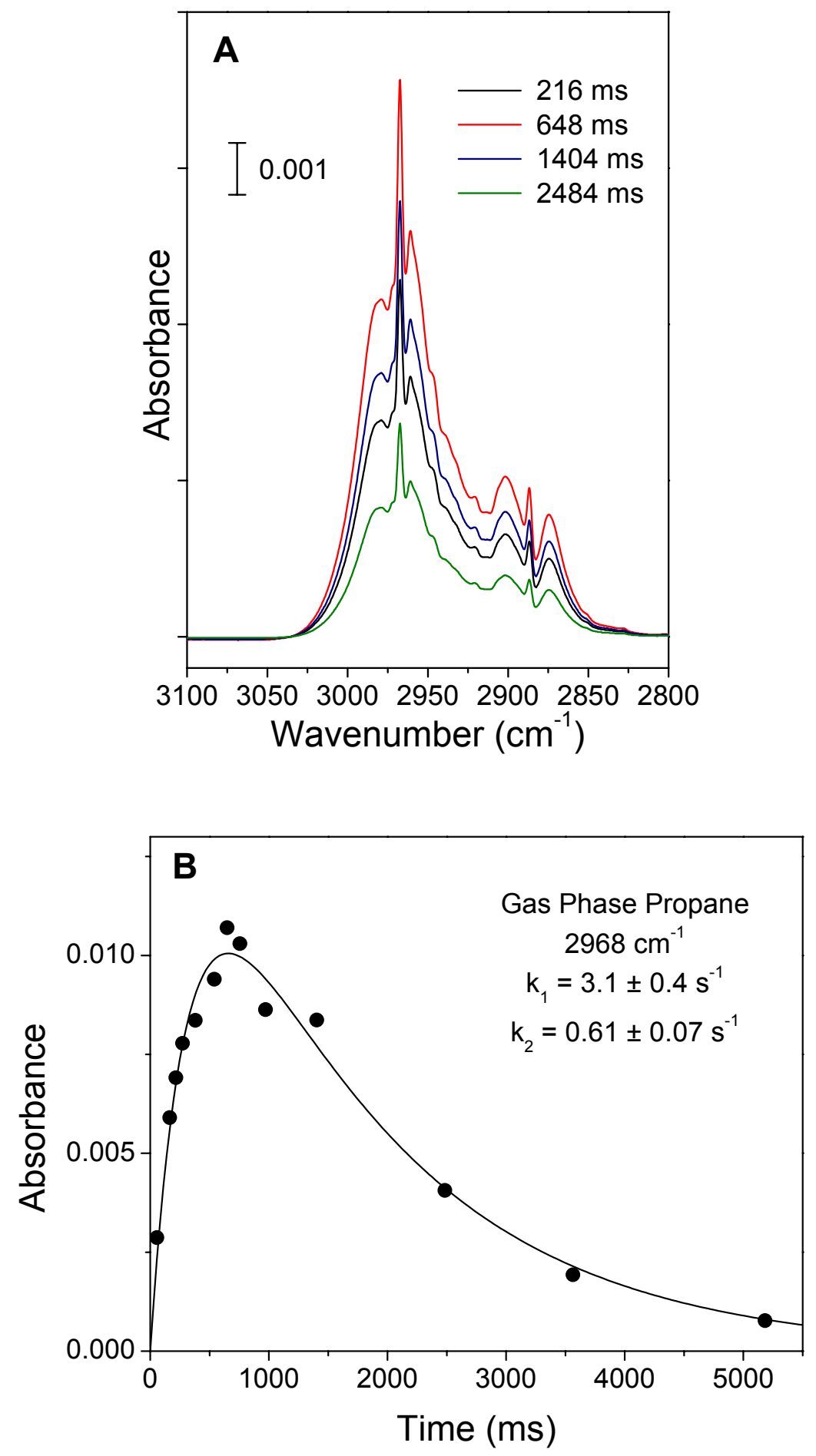

Figure 6. Rapid-scan spectra of $\mathrm{C}_{3} \mathrm{H}_{6}+\mathrm{H}_{2}$ catalysis at $383 \mathrm{~K}$. A: Spectral time slices showing the gas phase propane component at 216,648, 1404 and $2484 \mathrm{~ms}$ after initiation of catalysis. B: Kinetics of the peak absorbance of $2968 \mathrm{~cm}^{-1}$. The solid line represents a fit according to eq. 1. 

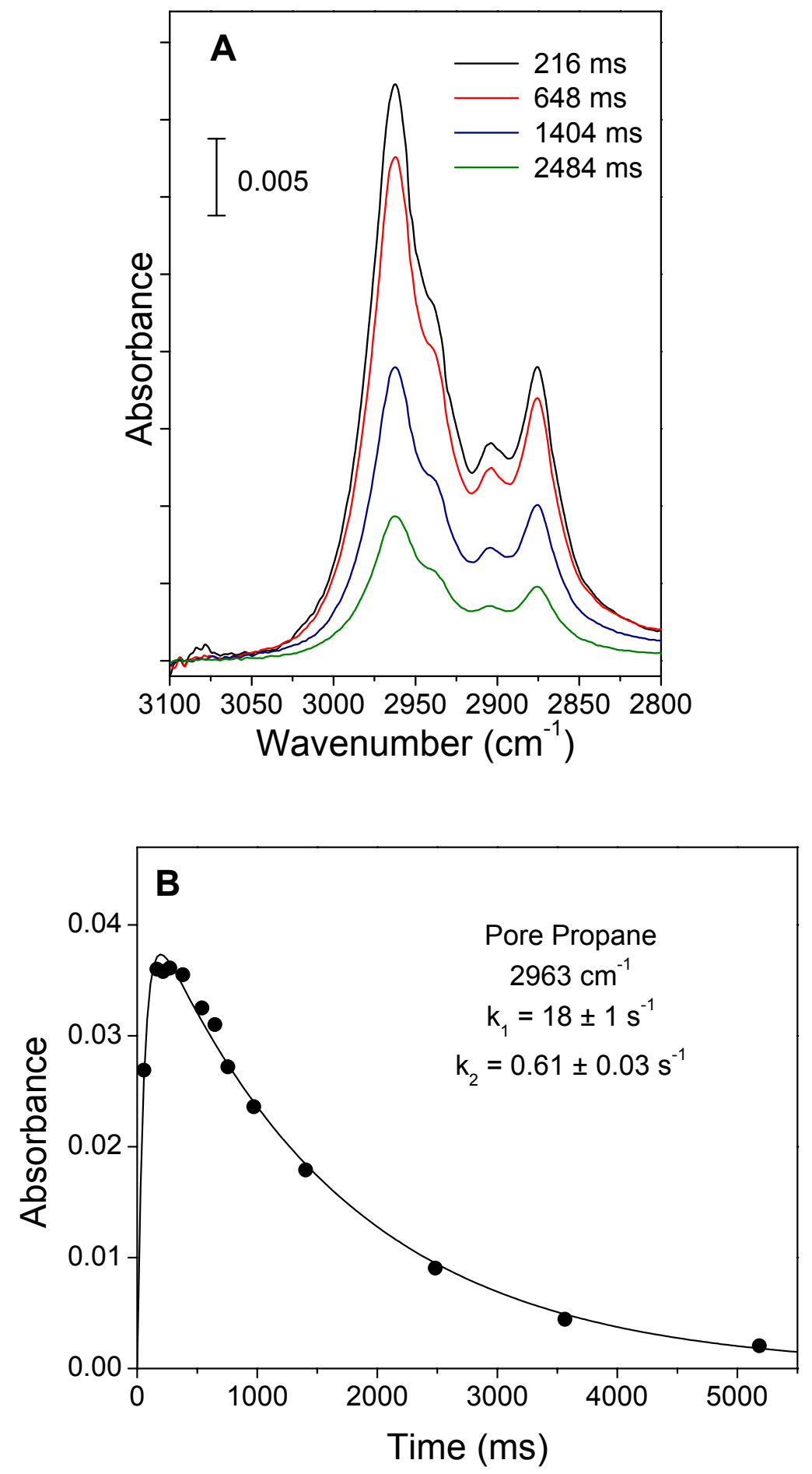

Figure 7. Rapid-scan spectra of $\mathrm{C}_{3} \mathrm{H}_{6}+\mathrm{H}_{2}$ catalysis at $383 \mathrm{~K}$. A: Spectral time slices showing the pore component of propane at 216,648, 1404, and $2484 \mathrm{~ms}$ after initiation of catalysis. B: Kinetics of peak absorbance of $2963 \mathrm{~cm}^{-1}$. The solid line represents a fit according to eq. 1 . 


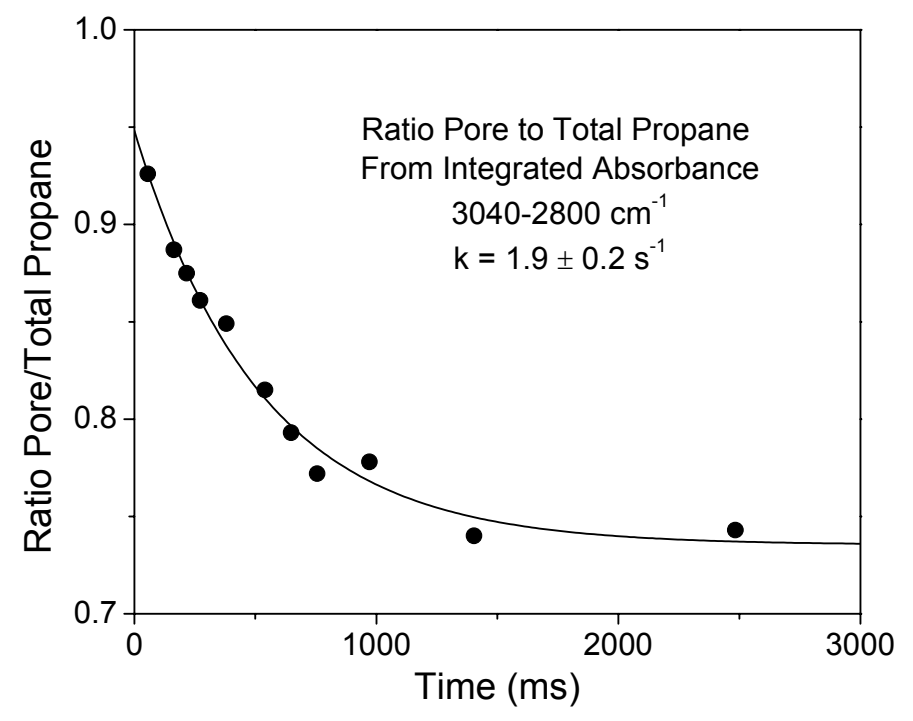

Figure 8. Temporal behavior of propane inside pores as fraction of total amount of propane upon $\mathrm{C}_{3} \mathrm{H}_{6}+\mathrm{H}_{2}$ catalysis at $383 \mathrm{~K}$. The ordinate represents the ratio of the integrated absorbance of propane inside pores (spectra of Figure 7) and the integrated absorbance of the observed propane band (spectra of Figure 5). 


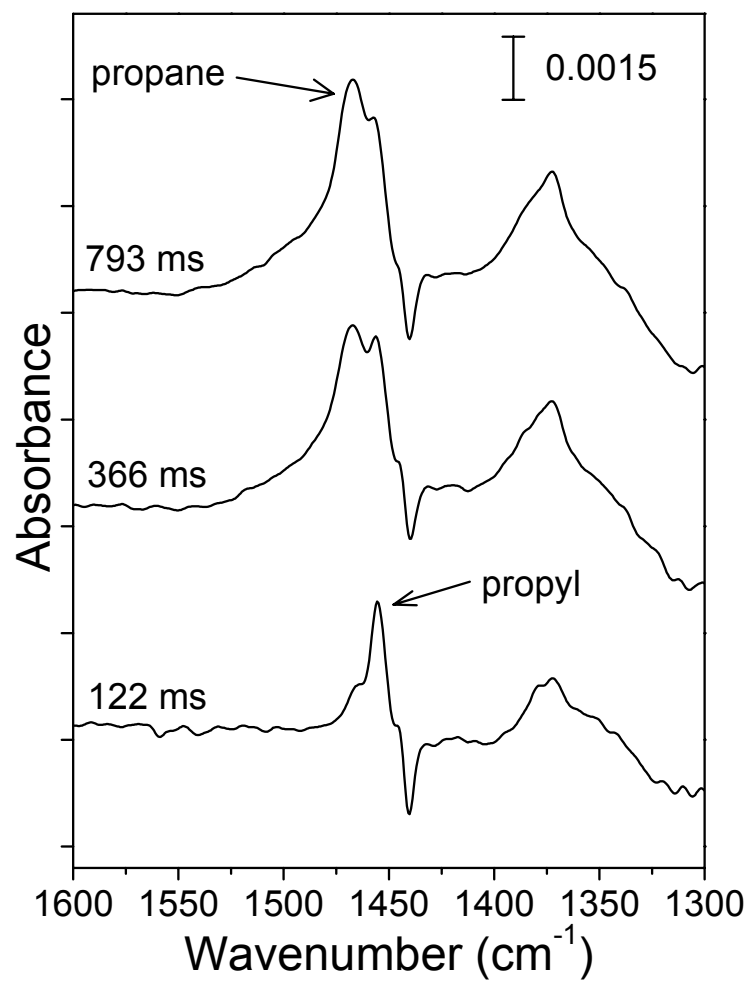

Figure 9. Rapid-scan spectra of $\mathrm{C}_{3} \mathrm{H}_{6}+\mathrm{H}_{2}$ catalysis at $323 \mathrm{~K}$. Spectral time slices showing the pore component of propane at 122,366, and $793 \mathrm{~ms}$ after initiation of catalysis. 